\title{
The association between whole body sagittal balance and risk of falls among elderly patients seeking treatment for back pain
}

J. Kim,

J. Y. Hwang,

J. K. Oh,

M. S. Park,

S. W. Kim,

H. Chang,

T-H. Kim

Spine Centre, Hallym

University Sacred

Heart Hospital, Hallym

University College of

Medicine, Anyang,

Korea
घ. Kim, MD, Professor, Department of Pediatrics,

Kangdong Sacred Heart Hospital,

Hallym University College of

Medicine, Seoul, Korea.

J. Y. Hwang, MD, Resident,

- J. K. Oh, MD, Professor,

M. S. Park, MD, Professor,

S. W. Kim, MD, Professor,

H. Chang, MD, Professor,

- T-H. Kim, MD, Professor,

n Spine Centre, Hallym University

Sacred Heart Hospital, Hallym

University College of Medicine,

Anyang, Korea.

Correspondence should be sent to

T-H. Kim; email:

paragon0823@gmail.com

doi: $10.1302 / 2046-3758.65 . B \mid R-$ 2016-0271.R2

Bone Joint Res 2017;6:337-344.

Received: 11 October 2016;

Accepted: 23 March 2017

\section{Objectives}

The objective of this study was to assess the association between whole body sagittal balance and risk of falls in elderly patients who have sought treatment for back pain. Balanced spinal sagittal alignment is known to be important for the prevention of falls. However, spinal sagittal imbalance can be markedly compensated by the lower extremities, and whole body sagittal balance including the lower extremities should be assessed to evaluate actual imbalances related to falls.

\section{Methods}

Patients over 70 years old who visited an outpatient clinic for back pain treatment and underwent a standing whole-body radiograph were enrolled. Falls were prospectively assessed for 12 months using a monthly fall diary, and patients were divided into fallers and non-fallers according to the history of falls. Radiological parameters from whole-body radiographs and clinical data were compared between the two groups.

\section{Results}

A total of 144 patients (120 female patients and 24 male patients) completed a 12-month follow-up for assessing falls. A total of 31 patients (21.5\%) reported at least one fall within the 12-month follow-up. In univariate logistic regression analysis, the risk of falls was significantly increased in older patients and those with more medical comorbidities, decreased lumbar lordosis, increased sagittal vertical axis, and increased horizontal distance between the C7 plumb line and the centre of the ankle (C7A). Increased C7A was significantly associated with increased risk of falls even after multivariate adjustment.

\section{Conclusion}

Whole body sagittal balance, measured by the horizontal distance between the $\mathrm{C} 7$ plumb line and the centre of the ankle, was significantly associated with risk of falls among elderly patients with back pain.

Cite this article: Bone Joint Res 2017;6:337-344.

Keywords: Whole body sagittal balance, Spinal sagittal balance, Fall, Elderly patients, Back pain

\section{Article focus}

- Whole body sagittal balance, measured by the horizontal distance between the C7 plumb line and the centre of the ankle, was significantly associated with risk of falls among elderly patients with back pain.

\section{Key messages}

- Balanced spinal sagittal alignment is known to be important for the prevention of falls.
Whole body sagittal balance, measured by the horizontal distance between the C7 plumb line and the centre of the ankle, was significantly associated with risk of falls among elderly patients with back pain.

\section{Strengths and limitations}

- Previous studies about the association between falls and spinal sagittal alignment did not show consistent results. 
- Further large-scale population-based prospective studies using advanced image technology such as biplanar radiography are required to validate the results of our study.

\section{Introduction}

Falls occur in $30 \%$ of over 65 -year-olds every year, ${ }^{1,2}$ and account for $10 \%$ of emergency department visits and $6 \%$ of hospitalisations. ${ }^{1,3-6}$ The risk factors for a fall have been identified in multiple studies,1,7-10 and these include postural hypotension, the use of multiple medications and impairment in cognition, vision, balance, gait and strength.

In past decades, spinal sagittal alignment received attention due to its strong relationship with falls. Spinal sagittal alignment is closely related to postural instability, ${ }^{11-16}$ and patients with abnormal sagittal balance showed an increased risk of falls. ${ }^{11,15,17-20}$ Moreover, according to Kapandji, ${ }^{21}$ the resistance to axial stress of a spine with physiological thoracolumbar curvature is five times that of a flattened spine, and physiological spinal sagittal curvature can act as a shock absorber. In other words, good spinal sagittal alignment can even act as a direct preventive factor against the prevention of vertebral fractures.

However, spinal sagittal balance cannot reflect the natural compensation mechanism of the lower extremities. ${ }^{22}$ For example, positive spinal sagittal imbalance leads to pelvic (posterior pelvic tilting) and lower limb (hip extension, knee flexion and ankle dorsiflexion posture) compensation mechanisms. ${ }^{23,24}$

In line with these concepts, we hypothesised that individual standing balance to estimate actual risk of a fall should be evaluated by "whole body" sagittal alignment. As the first study to evaluate the effect of whole body sagittal alignment on a fall, a prospective comparative study was designed, and several clinical and radiological parameters measured from whole-body radiographs were compared between 'fallers' and 'non-fallers'.

\section{Materials and Methods}

Patient enrolment. The study population comprised of patients over 70 years of age, who visited an outpatient clinic for back pain treatment and underwent a standing whole-body radiograph and lateral flexion-extension radiograph of the lumbar spine. Anteroposterior, lateral (neutral) and lateral flexion-extension radiographs of the lumbar spine were routinely performed for all patients with back pain. Standing whole-body radiographs were especially recommended for patients with walking difficulty to find out the causes such as fracture, deformity or degenerative disease of lower extremity. The choice of whole-body radiographs was entirely made by patients. Eligibility criteria included the ability to walk without walking aids (the ability to walk without an appliance, e.g. cane, crutches or wheelchair), and sufficient vision for gait (walking outside not limited by eyesight) based on a questionnaire.

Patients were excluded if they met any of the following criteria: history of recent (within six months) fracture or surgery on the spine or a lower extremity which would affect their ability to walk (36 patients); motor weakness or sensory deficit of a lower extremity (seven patients); known psychiatric or neurodegenerative disorders that may affect walking (14 patients); and occurrence of a specific event during 12-month follow-up (which could affect body alignment) such as fracture or surgery on the spine or a lower extremity (25 patients).

Comprehensive demographic, were conducted radiological and fall assessments by trained study staff as outlined below.

Assessment by interview. Sociodemographic characteristics assessed in the interview included age, gender, and level of education. Height and weight for body mass index (BMI) were measured. A medical history was obtained from every patient based on the Charlson comorbidity index, ${ }^{25}$ a validated instrument as a predictor of morbidity due to comorbid conditions.

Patients who visited an outpatient clinic for back pain treatment were initially enrolled in our study, so their back pain and disability were also assessed by visual analogue scale (VAS) scores of back pain and Oswestry disability index (ODI) scores, respectively.

Whole-body radiographs. Standing anteroposterior and lateral radiographs of the whole body were obtained with the subject in a comfortable upright position, with his or her arms positioned on a clavicle support, with their head facing forward. The detector to tube distance was $508 \mathrm{~cm}$, and images were obtained by five individual $(35 \times 43 \mathrm{~cm}$ ) cuts (Innovision DR; Shimadzu Corp., Kyoto, Japan). The five images were combined to form a composite image, which was transferred to the picture archiving and communication system (PACS) workstation (PiviewSTAR 5051, Infinitt Healthcare Co. Ltd, Seoul, Korea). Five separate DR images were obtained using 68 $\mathrm{kVp}$ to $93 \mathrm{kVp}$ and $28 \mathrm{mAs}$ to $90 \mathrm{mAs}$ according to the location of the individual cut.

Assessment of radiological parameters. All radiological parameters were measured twice, at one-week intervals, by two fellowship-trained orthopaedic spine surgeons (MSP and T-HK) blinded to all clinical information, and the average values of both observers were used.

With the whole-body lateral radiograph, we used three reference points: posterosuperior corner of S1; knee centre; and centre of the ankle. The centre of the knee was defined as the midpoint between the lowest points of two femoral condyles, and the centre of the ankle was defined as the midpoint between the highest points of two talar domes (Fig. 1). Three reference lines were additionally used (Fig. 2) and, finally, we defined nine radiological parameters using three reference points and three reference lines. At the first, the centre 


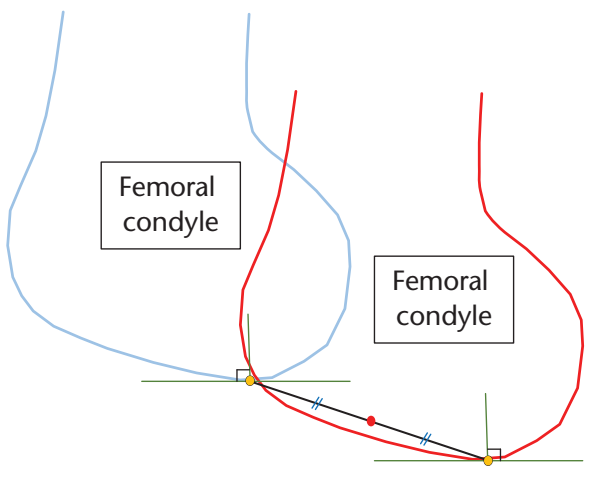

Fig. $1 \mathrm{a}$

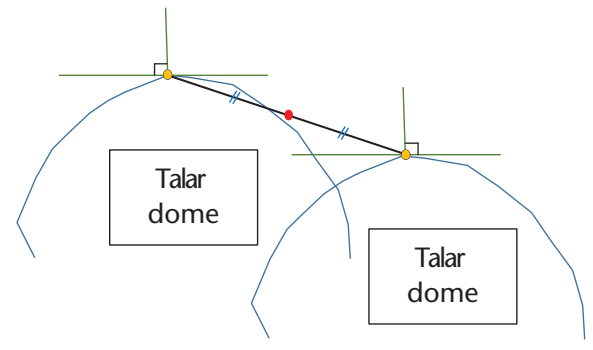

Fig. $1 \mathrm{~b}$

Centre of a) knee joint, b) ankle joint. The red spots represent the centre of each joint.

Table I. Intraclass correlation coefficients (ICCs) for whole body radiological parameters

\begin{tabular}{|c|c|c|}
\hline & Intra-observer ICC & Interobserver ICC \\
\hline Horizontal distance between the COG and the posterosuperior corner of S1 (COGS) & $0.899(0.859$ to 0.927$)$ & 0.845 (0.785 to 0.899$)$ \\
\hline Horizontal distance between the COG and the knee centre (COGK) & 0.867 (0.815 to 0.904$)$ & 0.805 (0.729 to 0.860$)$ \\
\hline Horizontal distance between the COG and the centre of the ankle (COGA) & 0.830 (0.763 to 0.877$)$ & $0.740(0.639$ to 0.813$)$ \\
\hline Horizontal distance between the $\mathrm{C} 2$ plumb line and the posterosuperior corner of $\mathrm{S} 1$ (C2S) & 0.965 (0.951 to 0.974$)$ & 0.928 (0.899 to 0.948$)$ \\
\hline Horizontal distance between the $\mathrm{C} 2$ plumb line and the knee centre (C2K) & $0.952(0.934$ to 0.966$)$ & 0.906 (0.869 to 0.932$)$ \\
\hline Horizontal distance between the $\mathrm{C} 2$ plumb line and the centre of the ankle (C2A) & $0.942(0.919$ to 0.958$)$ & $0.880(0.833$ to 0.914$)$ \\
\hline Horizontal distance between the $C 7$ plumb line and the knee centre (C7K) & 0.930 (0.903 to 0.950$)$ & 0.893 (0.851 to 0.923$)$ \\
\hline Horizontal distance between the $C 7$ plumb line and the centre of the ankle (C7A) & 0.889 (0.845 to 0.920$)$ & 0.849 (0.790 to 0.891$)$ \\
\hline
\end{tabular}

of gravity of the head (COG) was defined as the anterior margin of the external auditory canal according to previous reports, ${ }^{26-28}$ and its vertical axis was used as the first reference line (Fig. 2a). The horizontal distance between the COG and the posterosuperior corner of S1 was defined as COGS. The horizontal distance between the COG and the knee centre was defined as COGK. The horizontal distance between the COG and the centre of the ankle was defined as COGA. Next, the C2 plumb line was used as the second reference line (Fig. 2b). The horizontal distance between the $\mathrm{C} 2$ plumb line and the posterosuperior corner of S1 was defined as C2S. The horizontal distance between the $\mathrm{C} 2$ plumb line and the knee centre was defined as $\mathrm{C} 2 \mathrm{~K}$. The horizontal distance between the $\mathrm{C} 2$ plumb line and the centre of the ankle was defined as $\mathrm{C} 2 \mathrm{~A}$. Finally, the $\mathrm{C} 7$ plumb line was used as the third reference line (Fig. 2C). The horizontal distance between the $\mathrm{C} 7$ plumb line and the posterosuperior corner of S1 was defined as C7S. The horizontal distance between the $\mathrm{C} 7$ plumb line and the knee centre was defined as C7K. The horizontal distance between the $\mathrm{C} 7$ plumb line and the centre of the ankle was defined as C7A.

The following radiological measurements were also taken from the whole-body radiograph: Lumbar lordosis was defined as the angle subtended by the superior endplate line of L1 and the endplate line of S1. Thoracic kyphosis was defined as the angle between T4 and T12 by the Cobb method. ${ }^{29}$ Cervical lordosis was defined as the angle of the inferior endplates of $\mathrm{C} 2$ and $\mathrm{C} 7$, and the
T1 slope was measured as the angle between a horizontal line and the superior endplate of $\mathrm{T} 1$. Three pelvic parameters (pelvic incidence (PI), sacral slope (SS) and pelvic tilt (PT)) were also measured from the whole-body radiograph. ${ }^{30}$ Additionally, lumbar range of motion was defined as the difference between lumbar lordosis (L1-S1) in lateral flexion and extension radiograph.

Assessment of degenerative change in the spine and lower extremity. The presence of symptomatic osteoarthritis of the hip, knee and ankle was evaluated from whole-body anteroposterior radiographs by the Kellgren-Lawrence system. ${ }^{31}$ The presence of symptomatic lumbar spinal stenosis was also evaluated. The diagnosis of symptomatic lumbar spinal stenosis was established by the presence radiculopathy and neurogenic claudication, with low back pain confirmed by degenerative changes at the relevant level based on radiographs.

Assessment of prospective falls during the $\mathbf{1 2}$ months of follow-up. When monitoring falls in cohort studies of older people, researchers are advised to gather information on falls on a weekly or monthly basis. ${ }^{32}$ In our study, falls were assessed over a 12-month period using a monthly fall diary, and the diary was also confirmed with a telephone reminder call every three months. For patients who had difficulty in recording a fall diary, their history of falls was assessed by monthly telephone call. The causes of falls were also recorded. However, falls due to syncope, dizziness or extrinsic causes such as a traffic accident were not recorded as a fall in our statistical analysis. 


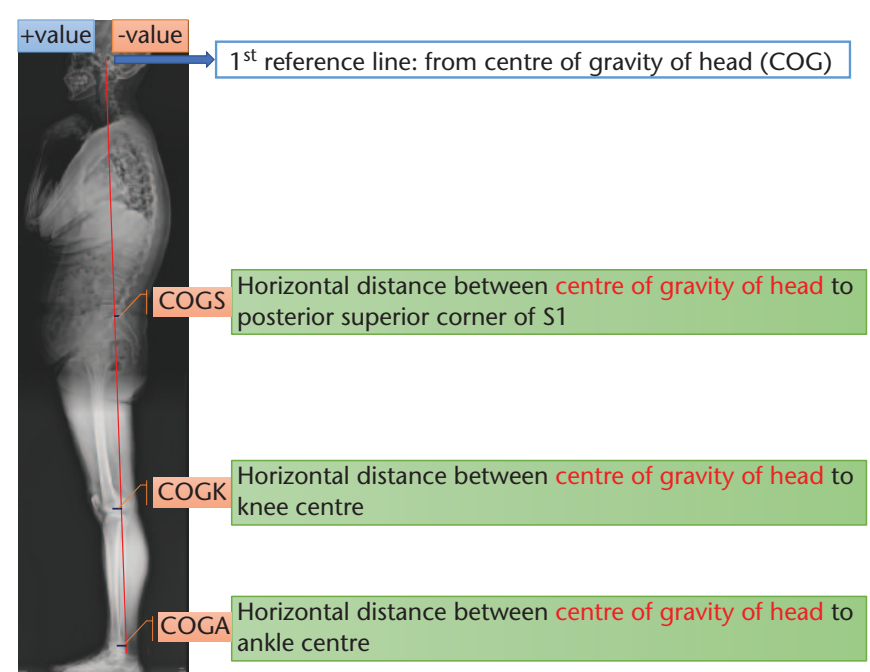

Fig. $2 a$

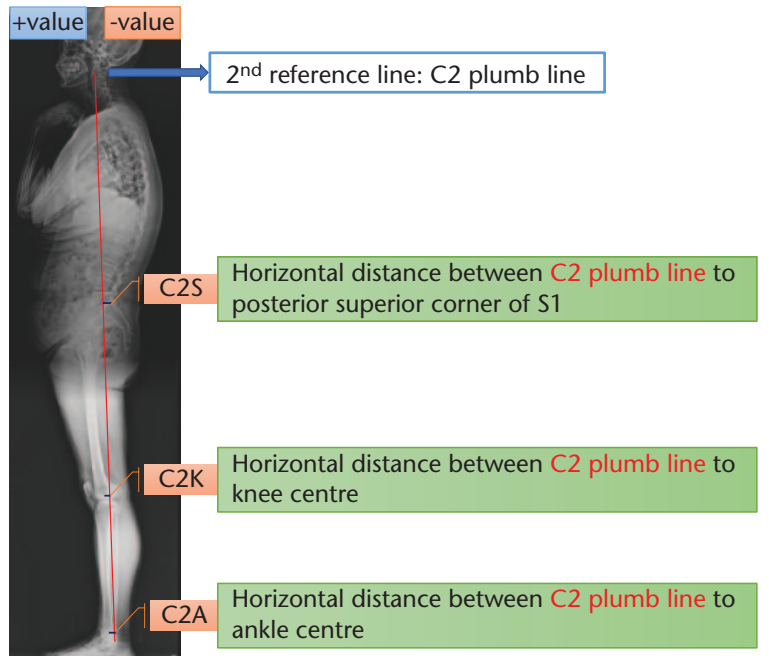

Fig. $2 b$

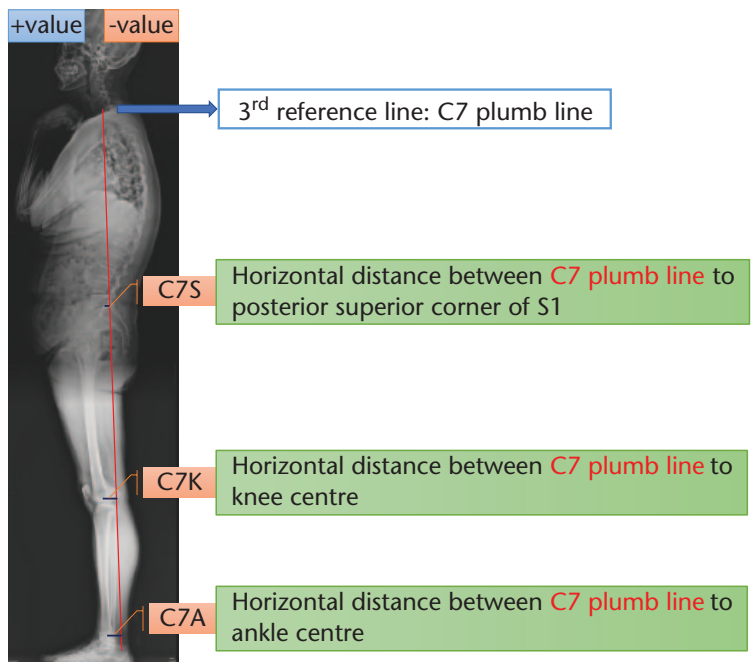

Fig. 2c

Lateral whole-body radiograph: parameters from a) centre of gravity of head (COG); b) C2 plumb line; and c) C7 plumb line.

Table II. Comparison of patient characteristics

\begin{tabular}{|c|c|c|c|}
\hline & Level of education & Faller & Non-faller \\
\hline Patients (n) (\%) & & $31(21.5)$ & $113(78.5)$ \\
\hline Age (yrs) (SD) & & $77.4(4.3)$ & $74.5(3.6)$ \\
\hline Gender (Male:female) & & $5: 26$ & 19:94 \\
\hline Body mass index (SD) & & $24.1(2.9)$ & $24.2(2.9)$ \\
\hline Medical comorbidity (SD) & & $1.8(0.9)$ & $1.4(0.8)$ \\
\hline \multirow[t]{3}{*}{ Education } & Less than high school & 28 & 91 \\
\hline & High school & 1 & 15 \\
\hline & College or college graduate & 2 & 7 \\
\hline Back pain Visual Analogue Score (0 to 10$)$ (SD) & & $6.0(1.7)$ & $5.5(1.5)$ \\
\hline Oswestry Disability Index ${ }^{33}$ score (SD) & & $40.2(16.3)$ & $35.0(17.7)$ \\
\hline Presence of symptomatic lumbar stenosis & & 15 & 38 \\
\hline Presence of symptomatic osteoarthritis of lower extremities & & 10 & 26 \\
\hline
\end{tabular}

Statistical analysis. Intraclass correlation coefficient (ICC) was used to assess the statistical significance of intraobserver and interobserver agreement for the new whole body balance parameters. Univariate logistic regression analysis was done to identify association between falls and independent variables. To identify significant 
273 patients were enrolled for eligibility

57 patients were excluded:

History of recent fracture or surgery (36 patients)

Motor weakness or sensory deficit of lower-extremity (7 patients)

Neurodegenerative disorders (12 patients)

Dementia: 8 patients

Parkinson's disease: 3 patients

Ataxia: 1 patient

Psychiatric disorder (2 patients)

Schizophrenia: 2 patients ( 1 patient was already excluded by combined dementia) Delusion: 1 patient

Refused to enrol: 23 patients

193 patients were enrolled for 12-month follow-up

Lost to follow-up: 24 patients

25 patients were additionally excluded.

Fracture or surgery of spine and lower extremity during follow-up: 13 patients

Diagnosis of Parkinson's disease during follow-up: 3 patients

Diagnosis of dementia during follow-up: 2 patients

Cerebrovascular attack during follow-up: 5 patients

Dying during follow-up: 2 patients

144 patients finished 12-month follow-up

Fig. 3

Enrolment and follow-up of the study participants. COG, centre of gravity of the head.

Table III. Comparison of radiological parameters between fallers and non-fallers (mean with standard deviation in brackets)

\begin{tabular}{|c|c|c|}
\hline & Faller & Non-faller \\
\hline Lumbar range of motion & $24.6(10.2)$ & $29.6(14.0)$ \\
\hline Lumbar lordosis & $28.9(13.2)$ & $34.2(12.2)$ \\
\hline Pelvic tilt & $26.4(11.1)$ & $24.2(10.2)$ \\
\hline Sacral slope & $28.7(11.3)$ & $29.1(10.0)$ \\
\hline Pelvic incidence & $55.1(10.8)$ & $53.3(10.1)$ \\
\hline Thoracic kyphosis & $29.8(16.3)$ & $38.8(31.5)$ \\
\hline T1 slope & $26.3(9.2)$ & $29.0(7.0)$ \\
\hline Cervical lordosis & $18.4(10.9)$ & $14.9(9.0)$ \\
\hline Horizontal distance between the COG and the posterosuperior corner of S1 (COGS) & $61.7(55.8)$ & $49.7(43.1)$ \\
\hline Horizontal distance between the COG and the knee centre (COGK) & $-4.4(50.7)$ & $-7.3(36.6)$ \\
\hline Horizontal distance between the COG and the centre of the ankle (COGA) & $32.7(37.1)$ & $20.8(33.8)$ \\
\hline Horizontal distance between the $\mathrm{C} 2$ plumb line and the posterosuperior corner of $\mathrm{S} 1(\mathrm{C} 2 \mathrm{~S})$ & $73.4(58.7)$ & $60.1(42.0)$ \\
\hline Horizontal distance between the $\mathrm{C} 2$ plumb line and the knee centre (C2K) & $7.4(56.5)$ & $3.1(36.4)$ \\
\hline Horizontal distance between the $\mathrm{C} 2$ plumb line and the centre of the ankle (C2A) & $44.5(42.0)$ & $31.2(33.4)$ \\
\hline Horizontal distance between the $\mathrm{C} 7$ plumb line and the posterosuperior corner of S1 (C7S) & $64.0(56.7)$ & $44.6(40.1)$ \\
\hline Horizontal distance between the $C 7$ plumb line and the knee centre (C7K) & $-2.0(51.1)$ & $-11.6(32.8)$ \\
\hline Horizontal distance between the $\mathrm{C} 7$ plumb line and the centre of the ankle (C7A) & $35.1(37.4)$ & $16.5(29.9)$ \\
\hline
\end{tabular}

radiological parameters associated with a fall, multivariate adjustment was done. For statistical analysis, SPSS 17.0 (IBM Corp, Armonk, New York) was used.

\section{Results}

A total of 144 patients (120 female patients and 24 male patients) completed 12 months of follow-up for assessing falls (Fig. 3). The mean age was 75.2 years. According to their fall history, patients were divided into fallers and non-fallers. A total of 31 patients (21.5\%) reported at least one fall within the 12-month follow-up. ICC values for the whole body balance parameters were greater than 0.8 except for interobserver ICC of COGA (Table I).

Comparison of independent variables between fallers and non-fallers. The mean age of patients was 77.4 years for fallers, and 74.5 years for non-fallers (Table II). Independent variables about patient characteristics were compared between faller and non-faller in Table II.

All radiological parameters were also compared between fallers and non-fallers (Table III).

Association between falls and independent variables. Univariate logistic regression analysis was done to identify association between falls and independent variables. 
Table IV. Association between falls and independent variables: univariate analysis

\begin{tabular}{|c|c|c|}
\hline Independent variable & Odds ratio & $\mathbf{9 5} \%$ confidence interval \\
\hline Age (yrs) & 1.211 & $(1.088$ to 1.349$)$ \\
\hline Medical comorbidity & 1.928 & (1.143 to 3.253$)$ \\
\hline Lumbar lordosis & 0.966 & (0.935 to 0.999$)$ \\
\hline Horizontal distance between the COG and the posterosuperior corner of S1 (COGS) & 1.006 & (0.997 to 1.015$)$ \\
\hline Horizontal distance between the COG and the knee centre (COGK) & 1.002 & (0.992 to 1.012$)$ \\
\hline Horizontal distance between the COG and the centre of the ankle (COGA) & 1.010 & (0.998 to 1.023$)$ \\
\hline Horizontal distance between the $\mathrm{C} 2$ plumb line and the posterosuperior corner of $\mathrm{S} 1$ (C2S) & 1.006 & (0.998 to 1.015$)$ \\
\hline Horizontal distance between the $\mathrm{C} 2$ plumb line and the knee centre $(\mathrm{C} 2 \mathrm{~K})$ & 1.002 & (0.993 to 1.012$)$ \\
\hline Horizontal distance between the $\mathrm{C} 2$ plumb line and the centre of the ankle $(\mathrm{C} 2 \mathrm{~A})$ & 1.011 & (0.999 to 1.022$)$ \\
\hline Horizontal distance between the $\mathrm{C} 7$ plumb line and the posterosuperior corner of S1 (C7S) & 1.010 & (1.001 to 1.019$)$ \\
\hline Horizontal distance between the $\mathrm{C} 7$ plumb line and the knee centre $(\mathrm{C} 7 \mathrm{~K})$ & 1.007 & (0.996 to 1.017$)$ \\
\hline Horizontal distance between the $C 7$ plumb line and the centre of the ankle $(C 7 A)$ & 1.019 & (1.006 to 1.033$)$ \\
\hline
\end{tabular}

Table V. Association between falls and radiological parameters: multivariate analysis

\begin{tabular}{|c|c|c|}
\hline Independent variable & Adjusted odds ratio* & $\mathbf{9 5} \%$ confidence interval \\
\hline Lumbar lordosis & 0.968 & (0.933 to 1.004$)$ \\
\hline Horizontal distance between the C7 plumb line and the posterosuperior corner of S1 (C7S) & 1.006 & (0.995 to 1.016$)$ \\
\hline Horizontal distance between the $\mathrm{C} 7$ plumb line and the centre of the ankle (C7A) & 1.016 & (1.001 to 1.030$)$ \\
\hline
\end{tabular}

*adjusted for age, medical comorbidity

VAS, Visual analogue scale; ODI, Owestry Disability Index.

Risk of a fall was significantly increased in older patients and those with more medical comorbidities, decreased lumbar lordosis, increased C7S, and increased C7A (Table IV).

Multivariate adjustment was done for factors that were significant in the univariate analysis (age, medical comorbidity) and additionally for visual analogue scale(VAS) back pain score and ODI score. Adjusted odd ratios of radiological parameters for a fall were estimated (Table V). After multivariate adjustment, lumbar lordosis and C7S were no longer associated with risk of falls. However, C7A was still significantly associated with risk of falls (Table $\mathrm{V}$ ).

\section{Discussion}

There have been consistent reports on the close association between falls and spinal alignment, ${ }^{11,15,17-20}$ and the following radiological parameters were identified as significant risk factors for falls or fracture: decreased thoracic kyphosis;12,17 decreased lumbar lordosis; $11,14,15,17$ decreased lumbar range of motion; ${ }^{15}$ decreased sacral inclination; ${ }^{14}$ increased ratio by thoracic kyphosis/lumbar lordosis; ${ }^{14}$ increased pelvic incidence; ${ }^{20}$ increased pelvic tilting; ${ }^{20}$ and increased sagittal vertical axis. ${ }^{14}$ However, the results of each radiological parameter did not show consistent associations with falls among the studies. For example, increased thoracic kyphosis is a significant risk factor in one study ${ }^{17}$ but not in other studies. ${ }^{11,15}$ In addition, an increased sagittal vertical axis (C7S) is a significant risk factor in one study ${ }^{14}$ but not in another study. ${ }^{17}$

Balanced spinal sagittal alignment is known to be important for the prevention of falls because it is closely related to back muscle strength, ${ }^{14,20}$ body balance ${ }^{34-36}$ and forward vision. ${ }^{14}$ However, spinal sagittal imbalance can be compensated by the lower extremities. ${ }^{37}$ Moreover, arthritis in the lower extremities ${ }^{38}$ or a disability of the lower extremities ${ }^{39}$ are also strong, independent risk factors of falls. Therefore, to evaluate whole body balance in relation to the actual risk of a fall, the concept of sagittal alignment should be extended from spinal sagittal alignment to whole body sagittal alignment including the lower extremities.

Our study has demonstrated that whole body sagittal balance, measured by the horizontal distance between the C7 plumb line and the centre of the ankle (C7A), is significantly associated with the risk of a fall even after multivariate adjustment (Table $\mathrm{V}$ ). Lumbar lordosis and sagittal vertical axis (C7A) were also significantly associated with the risk of a fall in univariate analysis, however, they were no longer significant after multivariate adjustment.

The main limitation of our study is that the study population was not the general population but were patients who visited an outpatient clinic for back pain treatment and underwent a standing whole-body radiograph. Conventional radiograph by direct radiological method was used to evaluate whole body alignment in our study, and it could not be justified ethically to use such a conventional radiological method only for the purpose of a clinical study. Inevitably, we enrolled only patients who had already completed a whole-body radiograph (due to various causes) before study planning. Using such a methodological design, we were able to enroll relatively large number of patients ( $n=144)$ even after strict exclusion (Fig. 3). However, the results of our study are at risk of bias due to this methodological design. Back pain is 
also associated with an increased risk of a fall 40,41 which can act as a strong confounding factor. The reason why the adjusted odds ratio for C7A is relatively low (odd ratio: 1.016) is closely related to the effect of such strong confounding factors. However, there were no differences in VAS back pain scores or ODI scores between fallers and non-fallers, and our results were also significant even after multivariate adjustment including back pain and ODI scores. Further large-scale studies based on 'general population' are required to clarify the association between whole body balance and risk of falls, and to propose cut-off values.

Another limitation of our study is that we did not use advanced radiological assessment with a lower dosage of radiation such as biplanar radiography. Conventional radiological assessment by the DR method is not free from vertical distortion and stitching error during the process of image acquisition. To reduce such errors, postprocessing of whole-body radiographs was routinely checked by three individuals (radiology technician, orthopaedic resident and orthopaedic spine surgeon) in our institute. Nevertheless, further prospective study using advanced image technology such as biplanar radiography is still required to validate the results of our study. In addition, we did not perform sample size calculation prior to the study, which limited additional statistical comparison between fallers and non-fallers.

Finally, several important confounders are not clearly demonstrated in our study. First, the cognitive status of the enrolled patients, which can influence as a possible confounder for the relationship to falls, was not investigated by a validated instrument. We only excluded patients with dementia based on the patients' reports. Second, the physical activity or strength of the enrolled patients were not clearly investigated. These can also influence as possible confounders independently of pain and disability evaluated by VAS score and ODI score in our study.

In conclusion, whole body sagittal imbalance, measured by the horizontal distance between the $C 7$ plumb line and the centre of the ankle, was significantly associated with risk of falls among elderly patients with back pain.

\section{References}

1. Tinetti ME, Speechley M, Ginter SF. Risk factors for falls among elderly persons living in the community. N Eng/ J Med 1988;319:1701-1707.

2. Campbell AJ, Reinken J, Allan BC, Martinez GS. Falls in old age: a study of frequency and related clinical factors. Age Ageing 1981;10:264-270.

3. Englander F, Hodson TJ, Terregrossa RA. Economic dimensions of slip and fall injuries. J Forensic Sci 1996;41:733-746.

4. Tinetti ME, Williams CS. Falls, injuries due to falls, and the risk of admission to a nursing home. N Engl J Med 1997;337:1279-1284.

5. Tinetti ME, Williams CS. The effect of falls and fall injuries on functioning in community-dwelling older persons. J Gerontol A Biol Sci Med Sci1998;53:M112-119.

6. Gill TM, Desai MM, Gahbauer EA, Holford TR, Williams CS. Restricted activity among community-living older persons: incidence, precipitants, and health care utilization. Ann Intern Med 2001;135:313-321.
7. Nevitt MC, Cummings SR, Hudes ES. Risk factors for injurious falls: a prospective study. J Gerontol 1991;46:M164-170.

8. Tinetti ME, Doucette J, Claus E, Marottoli R. Risk factors for serious injury during falls by older persons in the community. J Am Geriatr Soc 1995;43:1214-1221.

9. Morris R. Predicting falls in older women. Menopause Int 2007;13:170-177.

10. Sturnieks DL, Tiedemann A, Chapman K, et al. Physiological risk factors for falls in older people with lower limb arthritis. J Rheumato/ 2004;31:2272-2279.

11. Ishikawa Y, Miyakoshi N, Kasukawa Y, Hongo M, Shimada Y. Spinal sagittal contour affecting falls: cut-off value of the lumbar spine for falls. Gait Posture 2013:38:260-263.

12. O'Brien K, Culham E, Pickles B. Balance and skeletal alignment in a group of elderly female fallers and nonfallers. J Gerontol A Biol Sci Med Sci 1997;52:B221-226.

13. Sinaki M, Brey RH, Hughes CA, Larson DR, Kaufman KR. Balance disorder and increased risk of falls in osteoporosis and kyphosis: significance of kyphotic posture and muscle strength. Osteoporos Int 2005;16:1004-1010.

14. Imagama S, Ito Z, Wakao $\mathbf{N}$, et al. Influence of spinal sagittal alignment, body balance, muscle strength, and physical ability on falling of middle-aged and elderly males. Eur S J 2013;22:1346-1353.

15. Kasukawa Y, Miyakoshi N, Hongo M, et al. Relationships between falls, spinal curvature, spinal mobility and back extensor strength in elderly people. J Bone Miner Metab 2010;28:82-87.

16. Ishikawa Y, Miyakoshi N, Kasukawa Y, Hongo M, Shimada Y. Spinal curvature and postural balance in patients with osteoporosis. Osteoporos Int 2009;20:2049-2053

17. Kobayashi T, Takeda N, Atsuta Y, Matsuno T. Flattening of sagittal spinal curvature as a predictor of vertebral fracture. Osteoporos Int 2008;19:65-69.

18. Imagama S, Hasegawa $Y$, Matsuyama $Y$, et al. Influence of sagittal balance and physical ability associated with exercise on quality of life in middle-aged and elderly people. Arch Osteoporos 2011;6:13-20

19. Schneider DL, von Mühlen D, Barrett-Connor E, Sartoris DJ. Kyphosis does not equal vertebral fractures: the Rancho Bernardo study. J Rheumatol 2004;31:747-752.

20. Kim D-H, Choi D-H, Park J-H, Lee J-H, Choi Y-S. What is the effect of spinopelvic sagittal parameters and back muscles on osteoporotic vertebral fracture? Asian Spine J 2015;9:162-169.

21. Kapandji IA. The Physiology of the Joints. Vol. 3. The Trunk and the Vertebral Column. Second ed. Edinburgh: Churchill Livingstone, 1974.

22. Schwab F, Lafage V, Boyce R, Skalli W, Farcy JP. Gravity line analysis in adult volunteers: age-related correlation with spinal parameters, pelvic parameters, and foot position. Spine (Phila Pa 1976) 2006;31:E959-967.

23. Le Huec JC, Charosky S, Barrey C, Rigal J, Aunoble S. Sagittal imbalance cascade for simple degenerative spine and consequences: algorithm of decision for appropriate treatment. Eur Spine J 2011;20(Suppl 5):699-703.

24. Legaye J, Duval-Beaupère G, Hecquet J, Marty C. Pelvic incidence: a fundamental pelvic parameter for three-dimensional regulation of spinal sagittal curves. Eur Spine J 1998;7:99-103

25. Charlson ME, Pompei P, Ales KL, MacKenzie CR. A new method of classifying prognostic comorbidity in longitudinal studies: development and validation. J Chronic Dis 1987; 40:373-383.

26. Beier G, Schuck M, Schuller E, Spann W. Determination of physical data of the head. I. Center of gravity and moments of inertia of human heads. Virginia:DTIC Document, 1979

27. Yoshida G, Yasuda T, Togawa D, et al. Craniopelvic alignment in elderly asymptomatic individuals: analysis of 671 cranial centers of gravity. Spine (Phila Pa 1976) 2014;39:1121-1127.

28. Tang JA, Scheer JK, Smith JS, et al. The impact of standing regional cervical sagittal alignment on outcomes in posterior cervical fusion surgery. Neurosurgery 2015;76:S14-S21.

29. Rajnics P, Pomero V, Templier A, Lavaste F, Illes T. Computer-assisted assessment of spinal sagittal plane radiographs. J Spinal Disord 2001;14:135-142.

30. Duval-Beaupère G, Schmidt C, Cosson P. A Barycentremetric study of the sagittal shape of spine and pelvis: the conditions required for an economic standing position. Ann Biomed Eng 1992;20:451-462.

31. Kellgren JH, Lawrence JS. Radiological assessment of osteo-arthrosis. Ann Rheum Dis 1957;16:494-502.

32. Ganz DA, Higashi T, Rubenstein LZ. Monitoring falls in cohort studies of community-dwelling older people: effect of the recall interval. J Am Geriatr Soc 2005;53:2190-2194 
33. Kim D-Y, Lee S-H, Lee H-Y, et al. Validation of the Korean version of the oswestry disability index. Spine (Phila Pa 1976) 2005;30:E123-E127.

34. Maki BE, Holliday PJ, Topper AK. A prospective study of postural balance and risk of falling in an ambulatory and independent elderly population. J Gerontol 1994;49:M72-M84.

35. Pajala S, Era P, Koskenvuo M, et al. Force platform balance measures as predictors of indoor and outdoor falls in community-dwelling women aged 63-76 years. J Gerontol A Biol Sci Med Sci 2008;63:171-178.

36. Thapa PB, Gideon P, Brockman KG, Fought RL, Ray WA. Clinical and biomechanical measures of balance fall predictors in ambulatory nursing home residents. J Gerontol A Biol Sci Med Sci 1996:51:M239-M246.

37. Lee CS, Park SJ, Chung SS, Lee KH. The effect of simulated knee flexion on sagittal spinal alignment: novel interpretation of spinopelvic alignment. Eur Spine $J$ 2013:22:1059-1065

38. Sturnieks DL, Tiedemann A, Chapman K, et al. Physiological risk factors for falls in older people with lower limb arthritis. J Rheumato/ 2004;31:2272-2279.

39. Tinetti ME, Speechley M, Ginter SF. Risk factors for falls among elderly persons living in the community. N Eng J Med 1988;319:1701-1707.

40. Leveille SG, Bean J, Bandeen-Roche K, et al. Musculoskeletal pain and risk for falls in older disabled women living in the community. J Am Geriatr Soc 2002;50:671-678.
41. Leveille SG, Jones RN, Kiely DK, et al. Chronic musculoskeletal pain and the occurrence of falls in an older population. JAMA 2009;302:2214-2221.

\section{Funding Statement}

- None declared

Author Contributions

J. Kim: First author, Statistical analysis, English writing, Revision.

J. Y. Hwang: Co-author, Data collection, Writing paper.

J. K. Oh: Co-author, Data acquisition.

M. S. Park: Co-author, Data acquisition.

S. W. Kim: Co-author, Data acquisition.

H. Chang: Co-author, Data acquisition.

- T-H. Kim: Corresponding author, Study design and planning, Data acquisition, Statistical analysis, Writing paper.

ICMJE Conflicts of Interest

None declared

(c) $2017 \mathrm{Kim}$ et al. This is an open-access article distributed under the terms of the Creative Commons Attributions licence (CC-BY-NC), which permits unrestricted use, distribution, and reproduction in any medium, but not for commercial gain, provided the original author and source are credited. 